\title{
Improved Results on Finite Time Stability of Time Delay Systems: Jensen's Inequality-based Approach
}

\author{
DRAGUTIN LJ. DEBELJKOVIĆ, Megatrend University, \\ Faculty of Civil Aviation, Belgrade \\ Original scientific paper \\ UDC: $100.404,7$ \\ IVAN M. BUZUROVIĆ Medical Physics and \\ DOI: 10.5937/tehnika1801076D \\ Biophysics Division, Harvard Medical School Boston, MA, USA \\ GORAN V. SIMEUNOVIĆ University of Belgrade, \\ Faculty of Mechanical Engineering, Innovation Centre, Belgrade \\ DARKO M. RADOJEVIĆ, University of Belgrade, \\ Faculty of Mechanical Engineering, Belgrade
}

\begin{abstract}
In this study, finite-time stability of the linear continuous time-delay systems was investigated. A novel formulation of the Lyapunov-like function was used to develop a new sufficient delay-dependent condition for finite-time stability. The proposed function does not need to be positive-definite in the whole state space, and it does not need to have negative derivatives along the system trajectories. The proposed method was compared with the previously developed and reported methodologies. It was concluded that the stability investigation using the novel condition for stability investigation was less complicated for numerical calculations. Furthermore, it gives results in comparison with the ones obtained with other analyzed conditions, and it provides superior results for these class of systems.
\end{abstract}

Key words: Continuous time-delay systems, Finite time stability, Algebraic inequalities

\section{INTRODUCTION}

The concept of Lyapunov asymptotic stability is widely known in the control community. However, in some cases, Lyapunov asymptotic stability approach is not sufficient in the practical applications. Sometimes large values of state variables are not practically acceptable, for instance in the cases where saturation is present. In these cases, it is of particular significance to consider the behavior of dynamical systems only over a finite time interval. For this purpose, the concept of finite-time stability (FTS) can be used. For a system, it is said to be FTS once a time interval is fixed if its state does not exceed some bounds during this time interval.

This concept stability dates back to the 1950s [13]. Since then, the researchers' interest has moved toward the classical Lyapunov stability due to the lack of

Author's address: Dragutin Debeljković, Megatrend University, Faculty of Civil Aviation, Belgrade, Bulevar maršala Tolbuhina 8

e-mail: ddebeljkovic@yahoo.com

Paper received: 27.08.2017.

Paper accepted: 15.12.2017. operative test conditions for FTS. Recently, the concept of FTS has been revisited in the prospective of the linear matrix inequality theory, which has allowed the formulation of less conservative conditions that can guarantee both FTS and finite-time stabilization of the linear continuous time systems. Many valuable results have been obtained for this type of stability, such as the ones reported in [4-11]. Time delay and parameter uncertainty are commonly encountered in various technical systems, such as electric, pneumatic and hydraulic networks, chemical processes, and long transmission lines.

It has been shown that the existence of delay and uncertainty is the source of instability and poor performance of control systems.

Similar to the systems without delay, there is a need to investigate FTS for a class of time-delay systems. There are few results on FTS of time-delay systems. Some early results on FTS of time-delay systems can be found in [12-18]. The results of these investigations are conservative because they use boundedness proprieties of the system response, i.e, of the solution of system models.

Recently, based on the linear matrix inequality (LMI) theory, some results have been obtained for FTS 
for some particular classes of time-delay systems [1922].

In this article, a novel delay dependent condition for the finite-time stability of the linear continuous time-delay systems has been presented. To solve the problem of FTS, we used the Lyapunov-like method. The sufficient condition is expressed in the form of algebraic inequality. The computation of the proposed conditions was presented throughout the numerical example.

\section{PRELIMINARIES AND PROBLEM FORMULATION}

The following notations has been used throughout the article. Superscript "T" stands for matrix transposition. $\square^{n}$ denotes the $n$-dimensional Euclidean space and $\square^{n \times m}$ is the set of all real matrices having dimension $(n \times m) . F>0$ means that $F$ is real symmetric and positive definite and $F>G$ means that the matrix ( $F$ $G)$ is positive definite. $\mu(F)$ and $\mu_{2}(F)$, where $\mu_{2}(F)$ $=1 / 2 \lambda_{\max }\left(F+F^{\mathrm{T}}\right)$ are the matrix measures of matrix $F$ , respectively. Matrices are assumed to be compatible for algebraic operations if their dimensions are not explicitly stated.

Consider the following linear system with time delay:

$$
\dot{\mathbf{x}}(t)=A_{0} \mathbf{x}(t)+A_{1}(\mathbf{x}(t-\tau))
$$

with a known vector valued function of the initial conditions:

$$
\mathbf{x}(t)=\varphi(t), \quad t \in[-\tau, 0]
$$

where $\mathbf{x}(t) \in \square^{n}$ is the state vector, $\mathbf{u}(t) \in \square^{m}$ is the control input, $A_{0} \in \square^{n \times n}, A_{1} \in \square^{n \times n}$ and $B \in \square^{n \times m}$ are known constant matrices, $\tau$ is constant time delay. The initial condition, $\boldsymbol{\varphi}(t)$ is a continuous and differentiable vector-valued function of $t \in[-\tau, 0]$.

In this study, the finite-time stability of the class of systems (1) has been investigated.

Definition 1. Time-delay system (1) satisfying the given initial condition (2) is said to be finite-time stable (FTS) with respect to $\{\alpha, \beta, T\}$ if :

$$
\sup _{t \in[-\tau, 0]} \boldsymbol{\varphi}^{T}(t) \boldsymbol{\varphi}(t) \leq \alpha \Rightarrow \mathbf{x}(t)^{T} \mathbf{x}(t)<\beta, \forall t \in[0, T]
$$

Lemma 1. (Jensen's integral inequality) For any positive symmetric constant matrix $M \in \square^{n \times n}$, scalars $a, b$ satisfying $a<b$, a vector function $\mathbf{f}:[a, b] \rightarrow \square^{n}$ exists, such that the integrations are well defined, and:

$$
\left(\int_{a}^{b} \mathbf{f}(\theta) d \theta\right)^{T} M\left(\int_{a}^{b} \mathbf{f}(\theta) d \theta\right) \leq(b-a) \int_{a}^{b} \mathbf{f}^{T}(\theta) M \mathbf{f}(\theta) d \theta
$$

In the following part, some existing results on delay dependent stability conditions are presented. These stability conditions were used for comparison against the results derived in this study.

Theorem 1. The time-delayed system (1) with the function of initial conditions (2) is finite time stable with respect to $\{\alpha, \beta, T\}$ if there exists a positive scalar $\wp$ such that the following condition holds:

$$
e^{\Lambda_{\max } t}<\frac{\beta}{\alpha}, \quad \forall t \in \mathfrak{I}
$$

where:

$$
\begin{aligned}
\Lambda_{\max } & =\lambda_{\max }\left(\left(A_{0}^{T}+A_{0}\right)+\left(A_{1}^{T}+A_{1}\right)\right) \\
& +\tau \cdot \lambda_{\max }\left(\wp\left(A_{1} A_{0} A_{0}^{T} A_{1}^{T}+A_{1} A_{1} A_{1}^{T} A_{1}^{T}\right)+2 \frac{q^{2}}{\wp} I\right)
\end{aligned}
$$

with: $\wp>0, q>0$ and $\mathfrak{I}=[0, T]$, [17].

Theorem 2. Time-delayed system (1) with the function of initial conditions (2) is finite time stable with respect to $\{\alpha, \beta, T\}$ if there exists a positive scalar $\Lambda_{\max }$ such that the following condition holds:

$$
(1+\tau) e^{\Lambda_{\max } \cdot t}<\frac{\beta}{\alpha}, \quad \forall t \in \mathfrak{I}
$$

where:

$$
\begin{gathered}
\Lambda_{\max }=\lambda_{\max }(\Pi), \\
\Pi=\left(A_{0}^{T}+A_{0}\right)+A_{1} A_{1}^{T}+I
\end{gathered}
$$

with $\Pi$ being symmetric matrix with all eigenvalues defined over the set of real numbers, [18].

Theorem 3. Time-delayed system (1) with the function of initial conditions (2) is finite time stable with respect to $\{\alpha, \beta, T\}$ if non-negative scalars $\wp, \gamma_{1}$ $, \gamma_{2}, \gamma_{3}$ exist as well as positive definite symmetric matrices $P$ and $Q$ such that the following conditions holds, [21]:

$$
\begin{aligned}
& \Xi=\left(\begin{array}{cc}
A_{0}^{T} P+P A_{0}+Q-\wp P & P A_{1} \\
A_{1}^{T} P & -Q
\end{array}\right)<0 \\
& \gamma_{1} I<P<\gamma_{2} I, \quad 0<Q<\gamma_{3} I \\
& \left(\begin{array}{ccc}
-\gamma_{1} \beta e^{-\alpha T} & \gamma_{2} \sqrt{\alpha} & \gamma_{3} \sqrt{\alpha \tau} \\
* & -\gamma_{2} & 0 \\
* & * & -\gamma_{3}
\end{array}\right)<0
\end{aligned}
$$




\section{MAIN RESULT}

In this section, the Lyapunov-like approach was used in order to find sufficient delay dependent conditions of finite time stability for the time delayed systems.

In the following part, a lemma necessary for construction of the system aggregation function is presented.

It was observed that the novel result presented here is based on the result given in [23].

Lemma 2. Let a scalar aggregation function $V(y(t))$ be defined as:

$$
V(\mathbf{y}(t))=\mathbf{y}^{T}(t) \mathbf{y}(t)
$$

where vector $\mathbf{y}(t)$ is defined in the following manner:

$$
\mathbf{y}(t)=\mathbf{x}(t)+\int_{0}^{\tau} Q(\theta) \mathbf{x}(t-\theta) d \theta
$$

$Q(t)$ is $(n \times n)$ matrix which is continuous and differentiable over time interval $[0, \tau]$ satisfying the following differential matrix equation:

$$
\dot{Q}(\vartheta)=\left(A_{0}+Q(0)\right) Q(\vartheta), \quad \vartheta \in[0, \tau]
$$

with initial condition:

$$
Q(\tau)=A_{1}
$$

Then Euler derivative of $V(\mathbf{y}(t))$ is given as:

$$
\dot{V}(\mathbf{y}(t))=\mathbf{y}^{T}(t) \Xi \mathbf{y}(t)
$$

where:

$$
\Xi=\left(A_{0}+Q(0)\right)^{T}+\left(A_{0}+Q(0)\right)
$$

Proof. From (12), follows:

$$
\begin{aligned}
\dot{V}(\mathbf{y}(t)) & =\left(\dot{\mathbf{x}}^{T}(t)+\frac{d}{d t} \int_{0}^{\tau} \mathbf{x}^{T}(t-\theta) Q^{T}(\theta) d \theta\right) \times \\
& \times\left(\mathbf{x}(t)+\int_{0}^{\tau} Q(\eta) \mathbf{x}(t-\eta) d \eta\right) \\
& +\left(\mathbf{x}^{T}(t)+\int_{0}^{\tau} \mathbf{x}^{T}(t-\theta) Q^{T}(\theta) d \theta\right) \times \\
& \times\left(\dot{\mathbf{x}}(t)+\frac{d}{d t} \int_{0}^{\tau} Q(\eta) \mathbf{x}(t-\eta) d \eta\right)
\end{aligned}
$$

The further part of the proof is straightforward if the following expression $\frac{d}{d t} \int_{0}^{\tau} Q(\theta) \mathbf{x}(t-\theta) d \theta$ was explicitly specified.

In that sense, let us look at this expression after the derivation on the variable $\theta$ has been performed:

$\frac{d}{d \theta}(Q(\theta) \mathbf{x}(t-\theta))=\dot{Q}(\theta) \mathbf{x}(t-\theta)+Q(\theta) \frac{\partial}{\partial \theta}(\mathbf{x}(t-\theta))$

It is noticeable that:

$$
\frac{\partial}{\partial \theta}(x(t-\theta))=-\frac{\partial}{\partial t}(x(t-\theta))
$$

By substituting the previous equation into (19), the following equation can be obtained:

$\frac{d}{d \theta}(Q(\theta) \mathbf{x}(t-\theta))=\dot{Q}(\theta) \mathbf{x}(t-\theta)-Q(\theta) \frac{\partial}{\partial t}(\mathbf{x}(t-\theta))$

or after rearrangement:

$$
\begin{aligned}
Q(\theta) \frac{\partial}{\partial t}(\mathbf{x}(t-\theta)) & =\dot{Q}(\theta) \mathbf{x}(t-\theta) \\
& -\frac{d}{d \theta}(Q(\theta) \mathbf{x}(t-\theta))
\end{aligned}
$$

The previous relation can be further derived as:

$$
\frac{d}{d t}(Q(\theta) \mathbf{x}(t-\theta))=Q(\theta) \frac{\partial}{\partial t}(\mathbf{x}(t-\theta))
$$

so, by virtue of (23), the expression can be derived as:

$$
\begin{aligned}
& \frac{d}{d t} \int_{0}^{\tau} Q(\theta) \mathbf{x}(t-\theta) d \theta= \\
& \int_{0}^{\tau} Q(\theta) \mathbf{x}(t-\theta) d \theta-\frac{d}{d \theta} \int_{0}^{\tau} Q(\theta) \mathbf{x}(t-\theta) d \theta
\end{aligned}
$$

or

$$
\begin{aligned}
\frac{d}{d t} \int_{0}^{\tau} Q(\theta) \mathbf{x}(t-\theta) d \theta & =\int_{0}^{\tau} \dot{Q}(\theta) \mathbf{x}(t-\theta) d \theta \\
& -Q(\tau) \mathbf{x}(t-\tau) \\
& +Q(0) \mathbf{x}(t)
\end{aligned}
$$

By employing (15), the previous equation can be directly rewritten as:

$$
\begin{aligned}
\frac{d}{d t} \int_{0}^{\tau} Q(\theta) \mathbf{x}(t-\theta) d \theta & =\int_{0}^{\tau} \dot{Q}(\theta) \mathbf{x}(t-\theta) d \theta \\
& -A_{1} \mathbf{x}(t-\tau) \\
& +Q(0) \mathbf{x}(t)
\end{aligned}
$$


Equation (18) becomes:

$$
\begin{aligned}
& V(\mathbf{y}(t))= \\
& =\left(\begin{array}{l}
\mathbf{x}^{T}(t) A_{0}^{T}+\mathbf{x}^{T}(t-\tau) A_{1}^{T}+ \\
\dot{\tau} \int_{0}^{\tau} \mathbf{x}^{T}(t-\theta) \dot{Q}^{T}(\theta) d \theta-\mathbf{x}^{T}(t-\tau) A_{1}^{T}+\mathbf{x}^{T}(t) Q^{T}(0)
\end{array}\right) \times \\
& \times\left(\mathbf{x}(t)+\int_{0}^{\tau} Q(\eta) \mathbf{x}(t-\eta) d \eta\right)+ \\
& \left(\mathbf{x}^{T}(t)+\int_{0}^{\tau} \mathbf{x}^{T}(t-\theta) Q^{T}(\theta) d \theta\right) \times \\
& \times\left(\begin{array}{l}
A_{0} \mathbf{x}(t)+A_{1} \mathbf{x}(t-\tau)+ \\
\tau \cdot \\
+\int_{0}^{\tau} Q(\eta) \mathbf{x}(t-\eta) d \eta-A_{1} \mathbf{x}(t-\tau)+Q(0) \mathbf{x}(t)
\end{array}\right)
\end{aligned}
$$

or:

$$
\begin{aligned}
\dot{V}(\mathbf{y}(t)) & =\left(\begin{array}{c}
\mathbf{x}^{T}(t) A_{0}^{T}+\mathbf{x}^{T}(t) Q^{T}(0)+ \\
+\int_{0}^{\tau} \mathbf{x}^{T}(t-\theta) \dot{Q}^{T}(\theta) d \theta
\end{array}\right) \times \\
& \times\left(\mathbf{x}(t)+\int_{0}^{\tau} Q(\eta) \mathbf{x}(t-\eta) d \eta\right) \\
& +\left(\mathbf{x}^{T}(t)+\int_{0}^{\tau} \mathbf{x}^{T}(t-\theta) Q^{T}(\theta) d \theta\right) \times \\
& \times\left(A_{0} \mathbf{x}(t)+Q(0) \mathbf{x}(t)+\int_{0}^{\tau} \dot{Q}(\eta) \mathbf{x}(t-\eta) d \eta\right)
\end{aligned}
$$

After rearrangement, the previous equation can be expressed as follows:

$$
\begin{aligned}
& \dot{V}(\mathbf{y}(t))=\mathbf{x}^{T}(t)\left(\left(A_{0}^{T}+Q^{T}(0)\right)+\left(A_{0}+Q(0)\right)\right) \mathbf{x}(t) \\
& +\mathbf{x}^{T}(t) \int_{0}^{\tau}\left(A_{0}^{T} Q(\eta)+Q^{T}(0) Q(\eta)+\dot{Q}(\eta)\right) \mathbf{x}(t-\eta) d \eta \\
& +\left(\int_{0}^{\tau} \mathbf{x}^{T}(t-\theta)\left(Q^{T}(\theta) A_{0}+Q^{T}(\theta) Q(0)+\dot{Q}^{T}(\theta)\right) d \theta\right) \mathbf{x}(t) \\
& \quad+\int_{0}^{\tau} \int_{0}^{\tau} \mathbf{x}^{T}(t-\theta)\left(\dot{Q}^{T}(\theta) Q(\eta)+Q^{T}(\theta) \dot{Q}(\eta)\right) \mathbf{x}(t-\eta) d \theta d \eta
\end{aligned}
$$

By virtue of (14), one can get:

$$
\begin{aligned}
& \dot{V}(\mathbf{y}(t))=\mathbf{x}^{T}(t) \Xi \mathbf{x}(t) \\
& +\mathbf{x}^{T}(t) \int_{0}^{\tau}\left(A_{0}^{T}+Q^{T}(0)+A_{0}+Q(0)\right) Q(\eta) \mathbf{x}(t-\eta) d \eta \\
& +\left(\int_{0}^{\tau} \mathbf{x}^{T}(t-\theta) Q^{T}(\theta)\left(A_{0}^{T}+Q^{T}(0)+A_{0}+Q(0)\right) d \theta\right) \mathbf{x}(t) \\
& +\int_{0}^{\tau} \int_{0}^{\tau} \mathbf{x}^{T}(t-\theta)\left\{\begin{array}{l}
Q^{T}(\theta)\left(A_{0}^{T}+Q^{T}(0)\right) Q(\eta)+ \\
+Q^{T}(\theta)\left(A_{0}+Q(0)\right) Q(\eta)
\end{array}\right\} \mathbf{x}(t-\eta) d \theta d \eta
\end{aligned}
$$

$$
\begin{aligned}
\dot{V}(\mathbf{y}(t)) & =\mathbf{x}^{T}(t) \Xi \mathbf{x}(t) \\
& +\mathbf{x}^{T}(t) \Xi \int_{0}^{\tau} Q(\eta) \mathbf{x}(t-\eta) d \eta+ \\
& \left(\int_{0}^{\tau} \mathbf{x}^{T}(t-\theta) Q^{T}(\theta) d \theta\right) \Xi \mathbf{x}(t) \\
& +\int_{0}^{\tau} \int_{0}^{\tau} \mathbf{x}^{T}(t-\theta)\left(Q^{T}(\theta) \Xi Q(\eta)\right) \mathbf{x}(t-\eta) d \theta d \eta
\end{aligned}
$$

as well as:

$$
\begin{aligned}
& \dot{V}(\mathbf{y}(t))=\mathbf{x}^{T}(t) \Xi\left(\mathbf{x}(t)+\int_{0}^{\tau} Q(\eta) \mathbf{x}(t-\eta) d \eta\right) \\
& +\left(\int_{0}^{\tau} \mathbf{x}^{T}(t-\theta) Q^{T}(\theta) d \theta\right) \Xi\left(\mathbf{x}(t)+\int_{0}^{\tau} Q(\eta) \mathbf{x}(t-\eta) d \eta\right)
\end{aligned}
$$

and finally:

$$
\begin{aligned}
& \dot{V}(\mathbf{y}(t))=\mathbf{x}^{T}(t) \Xi \mathbf{y}(t)+\left(\int_{0}^{\tau} \mathbf{x}^{T}(t-\theta) Q^{T}(\theta) d \theta\right) \Xi \mathbf{y}(t) \\
& \dot{V}(\mathbf{y}(t))=\left(\mathbf{x}^{T}(t)+\int_{0}^{\tau} \mathbf{x}^{T}(t-\theta) Q^{T}(\theta) d \theta\right) \Xi \mathbf{y}(t) \\
& \dot{V}(\mathbf{y}(t))=\mathbf{y}^{T}(t) \Xi \mathbf{y}(t)
\end{aligned}
$$

what completes the proof, Q.E.D.

Theorem 4. Time-delayed system (1) with the function of initial conditions (2), having the following properties:

$$
\begin{gathered}
\sigma\left\{A_{0}\right\} \in \square \wedge \sigma\left\{A_{1}\right\} \in \square \\
\exists ! \lambda_{i}\left(A_{0}\right) \in C^{+} \\
\boldsymbol{\varphi}(t)=\left[\varphi_{1}(t) \varphi_{2}(t) \ldots \ldots . . \varphi_{n}(t)\right]^{T} \\
\varphi_{i}(t) \geq 0, \quad \forall i=1,2, \ldots . n, \quad \forall t \in[-\tau, 0]
\end{gathered}
$$

is finite time stable with respect to $\{\alpha, \beta, T\}$, if there exist a matrix $Q(\vartheta) \geq 0, \vartheta \in[0, \tau]$, being the general solution of (14) and if the following condition is satisfied:

$$
(1+\tau)(1+\psi) e^{\lambda_{\max }(\Xi) \cdot t}<\frac{\beta}{\alpha}, \quad \forall t \in \mathfrak{I}
$$

where:

$$
\begin{aligned}
& R=A_{0}+Q(0) \\
& \Xi=R^{T}+R \\
& \psi=\lambda_{\max }\left(Q(0) Q^{T}(0)\right) \frac{e^{2 \mu_{2}(R) \tau}-1}{2 \mu(R)}
\end{aligned}
$$




$$
\mu(R)=\frac{1}{2} \lambda_{\max }\left(R^{T}+R\right)
$$

and $Q(0)$ is positive definite solution of the following nonlinear transcendental matrix equation:

$$
e^{A_{0}+Q(0) \tau} Q(0)=A_{1}
$$

Proof. From (16), follows:

$$
\dot{V}(\mathbf{y}(t))=\mathbf{y}^{T}(t) \Xi \mathbf{y}(t) \leq \lambda_{\max }(\Xi) V(\mathbf{y}(t))
$$

By integrating (43) from 0 to $t$, with $t \in[0, T]$, it was obtained:

$$
V(\mathbf{y}(t))<e^{\lambda_{\max }(\Xi) \cdot t} \cdot V(0)
$$

From (12), one can find:

$$
\begin{aligned}
V(\mathbf{y}(0)) & =\mathbf{x}^{T}(0) \mathbf{x}(0)+2 \int_{0}^{\tau} \mathbf{x}^{T}(0) Q(\vartheta) \mathbf{x}(-\vartheta) d \vartheta \\
& +\left[\int_{0}^{\tau} Q(\vartheta) \mathbf{x}(-\vartheta) d \vartheta\right]^{T} \times \int_{0}^{\tau} Q(\vartheta) \mathbf{x}(-\vartheta) d \vartheta
\end{aligned}
$$

Based on the known inequality ${ }^{1}$, and with the particular choice of $\Gamma=I$, one can get:

$$
\begin{aligned}
& V(\mathbf{y}(0)) \leq \mathbf{x}^{T}(0) \mathbf{x}(0) \\
& \quad+\int_{0}^{\tau} \mathbf{x}^{T}(0) Q(\vartheta) Q^{T}(\vartheta) \mathbf{x}(0) d \vartheta \\
& \quad+\int_{0}^{\tau} \mathbf{x}^{T}(-\vartheta) \mathbf{x}(-\vartheta) d \vartheta \\
& \quad+\left(\int_{0}^{\tau} Q(\vartheta) \mathbf{x}(-\vartheta) d \vartheta\right)^{T} \times \int_{0}^{\tau} Q(\vartheta) \mathbf{x}(-\vartheta) d \vartheta
\end{aligned}
$$

Using the Jensen's integral inequality, as in Lemma 1 , the following inequalities are valid:

$$
\begin{aligned}
& V(\mathbf{y}(0)) \leq \mathbf{x}^{T}(0) \mathbf{x}(0) \\
& \quad+\int_{0}^{\tau} \mathbf{x}^{T}(0) Q(\vartheta) Q^{T}(\vartheta) \mathbf{x}(0) d \vartheta \\
& \quad+\int_{0}^{\tau} \mathbf{x}^{T}(-\vartheta) \mathbf{x}(-\vartheta) d \vartheta \\
& \quad+\tau \int_{0}^{\tau} \mathbf{x}^{T}(-\vartheta) Q^{T}(\vartheta) Q(\vartheta) \mathbf{x}(-\vartheta) d \vartheta
\end{aligned}
$$
with:

Introducing the general solution of (14), given

$$
\begin{gathered}
Q(\vartheta)=e^{R \vartheta} Q(0), \quad \vartheta \in[0, \tau] \\
R=A_{0}+Q(0)
\end{gathered}
$$

\footnotetext{
$\overline{1_{2} u^{T}(t) v(t-\tau) \leq u^{T}(t) \Gamma^{-1}} u(t)+v^{T}(t-\tau) \Gamma v(t-\tau), \Gamma>0$
}

and by substituting (48) into (47), the following expression is obtained:

$$
\begin{aligned}
& V(\mathbf{y}(0)) \leq \mathbf{x}^{T}(0) \mathbf{x}(0) \\
& +\int_{0}^{\tau} \mathbf{x}^{T}(0) e^{R \vartheta} Q(0) Q^{T}(0) e^{R^{T} \vartheta} \mathbf{x}(0) d \vartheta \\
& +\int_{0}^{\tau} \mathbf{x}^{T}(-\vartheta) \mathbf{x}(-\vartheta) d \vartheta \\
& +\tau \int_{0}^{\tau} \mathbf{x}^{T}(-\vartheta) Q^{T}(0) e^{R^{T} \vartheta} e^{R \vartheta} Q(0) \mathbf{x}(-\vartheta) d \vartheta
\end{aligned}
$$

or:

$$
\begin{aligned}
& V(\mathbf{y}(0)) \leq \mathbf{x}^{T}(0) \mathbf{x}(0) \\
& +\lambda_{\max }\left(Q(0) Q^{T}(0)\right) \int_{0}^{\tau} \lambda_{\max }\left(e^{R \vartheta} e^{R^{T} \vartheta}\right) \mathbf{x}^{T}(0) \mathbf{x}(0) d \vartheta \\
& +\int_{0}^{\tau} \mathbf{x}^{T}(-\vartheta) \mathbf{x}(-\vartheta) d \vartheta \\
& +\tau \int_{0}^{\tau} \lambda_{\max }\left(e^{R \vartheta} e^{R^{T} \vartheta}\right) \mathbf{x}^{T}(-\vartheta) Q^{T}(0) Q(0) \mathbf{x}(-\vartheta) d \vartheta
\end{aligned}
$$

and :

$$
\begin{aligned}
& V(\mathbf{y}(0)) \leq \mathbf{x}^{T}(0) \mathbf{x}(0) \\
& +\mathbf{x}^{T}(0) \mathbf{x}(0) \cdot \lambda_{\max }\left(Q(0) Q^{T}(0)\right) \int_{0}^{\tau} \lambda_{\max }\left(e^{R \vartheta} e^{R^{T} \vartheta}\right) d \vartheta \\
& +\int_{0}^{\tau} \mathbf{x}^{T}(-\vartheta) \mathbf{x}(-\vartheta) d \vartheta \\
& +\tau \lambda_{\max }\left(Q^{T}(0) Q(0)\right) \int_{0}^{\tau} \lambda_{\max }\left(e^{R \vartheta} e^{R^{T} \vartheta}\right) \mathbf{x}^{T}(-\vartheta) d \vartheta
\end{aligned}
$$

Based on Definition 1, one can find:

$$
\begin{aligned}
& V(y(0)) \leq \alpha \\
& +\alpha \lambda_{\max }\left(Q(0) Q^{T}(0)\right) \int_{0}^{\tau} \lambda_{\max }\left(e^{R \vartheta} e^{R^{T} \vartheta}\right) d \vartheta \\
& +\alpha \tau+\alpha \tau \lambda_{\max }\left(Q^{T}(0) Q(0)\right) \int_{0}^{\tau} \lambda_{\max }\left(e^{R \vartheta} e^{R^{T} \vartheta}\right) d \vartheta
\end{aligned}
$$

From Coppell's inequality given in the following form:

$$
\lambda_{\max }\left(e^{F t} \cdot e^{F^{T} t}\right) \leq e^{2 \mu(F) t}
$$

with $\mu(F)$ being any matrix measure, follows:

$$
\begin{aligned}
& V(y(0)) \leq \alpha(1+\tau)+ \\
& \quad \alpha(1+\tau) \lambda_{\max }\left(Q(0) Q^{T}(0)\right) \int_{0}^{\tau} e^{2 \mu(R) \vartheta} d \vartheta
\end{aligned}
$$

or : 


$$
\begin{aligned}
V(y(0)) & \leq \alpha(1+\tau)\left(1+\left.\lambda_{\max }\left(Q(0) Q^{T}(0)\right) \frac{e^{2 \mu(R) \vartheta}}{2 \mu(R)}\right|_{\vartheta=0} ^{\vartheta=\tau}\right) \\
& =\alpha(1+\tau)\left(1+\lambda_{\max }\left(Q(0) Q^{T}(0)\right) \frac{e^{2 \mu(R) \tau}-1}{2 \mu(R)}\right)
\end{aligned}
$$

and finally:

$$
V(y(0)) \leq \alpha(1+\tau)(1+\psi)
$$

Based on the crucial assumption of Theorem 4, in connection with definiteness of matrix Q (v) over prescribed time interval and using the assumption given in (36), follows:

$$
0<2 \int_{0}^{\tau} \mathbf{x}^{T}(t) Q(\eta) \mathbf{x}(t-\eta) d \eta
$$

what directly leads to:

$$
\mathbf{x}^{T}(t) \mathbf{x}(t) \leq V(\mathbf{y}(t))
$$

Taking into account (44) and (56), it follows:

$$
\begin{aligned}
\mathbf{x}^{T}(t) \mathbf{x}(t) & \leq V(\mathbf{y}(t)) \\
& \leq e^{\lambda_{\max }(\Xi) \cdot t} \cdot V(0) \\
& \leq \alpha(1+\tau)(1+\psi) e^{\lambda_{\max }(\Xi) \cdot t}
\end{aligned}
$$

Finally, condition (37) and the above inequality imply:

$$
\mathbf{x}^{T}(t) \mathbf{x}(t)<\beta, \quad \forall t \in \mathfrak{I}
$$

what was to be proven. Q.E.D.

Remark 1. It can be noticed that the sufficient condition (37) entirely depends on the existence of the solution of (42). This requires that nonlinear algebraic matrix equation (42) have a positive definitive solution for $Q(0)$.

Remark 2. The brief explanation of condition (36) leads towards the conclusion that the considered system is restricted to unstable time delay systems with monotone growing solutions.

\section{NUMERICAL EXAMPLE}

The main result is numerically analyzed throughout the results of Theorem 4 .

Example 1. The system of the following form has been given:

$$
\begin{gathered}
\dot{\mathbf{x}}(t)=A_{0} \mathbf{x}(t)+A_{1} \mathbf{x}(t-0.1) \\
A_{0}=\left(\begin{array}{ccc}
-1.7 & 1.7 & 0 \\
1.3 & -1 & 0.7 \\
0.7 & 1 & -0.6
\end{array}\right), \quad A_{1}=\left(\begin{array}{ccc}
1.5 & -1.7 & 0.1 \\
-1.3 & 1.5 & -0.3 \\
-0.7 & 1 & 0.1
\end{array}\right)
\end{gathered}
$$

It is possibile to show that:

$$
\begin{gathered}
\sigma\left\{A_{0}\right\}=\left\{\begin{array}{lll}
0.7125, & -2.8758, & -1.1367
\end{array}\right\} \\
\sigma\left\{A_{1}\right\}=\left\{\begin{array}{lll}
2.8606, & 0.1197, & 0.1197
\end{array}\right\}
\end{gathered}
$$

Consequently, all conditions given (36) are satisfied.

In order to verify the finite time stability of system, given (61), the system operation is simulated under the following conditions:

$$
\boldsymbol{\varphi}(t)=\left[\begin{array}{lll}
1 & 1 & 1
\end{array}\right]^{T}, \quad t \in[-\tau, 0] .
$$

It is noticeable that:

$$
\boldsymbol{\varphi}^{T}(t) \boldsymbol{\varphi}(t)=3=\alpha, \quad t \in[-\tau, 0]
$$

Figures 1 and 2 show the initial response $\mathbf{x}(t)$ and the norm of state vector $\mathbf{x}^{T}(t) \mathbf{x}(t)$ of system (61).

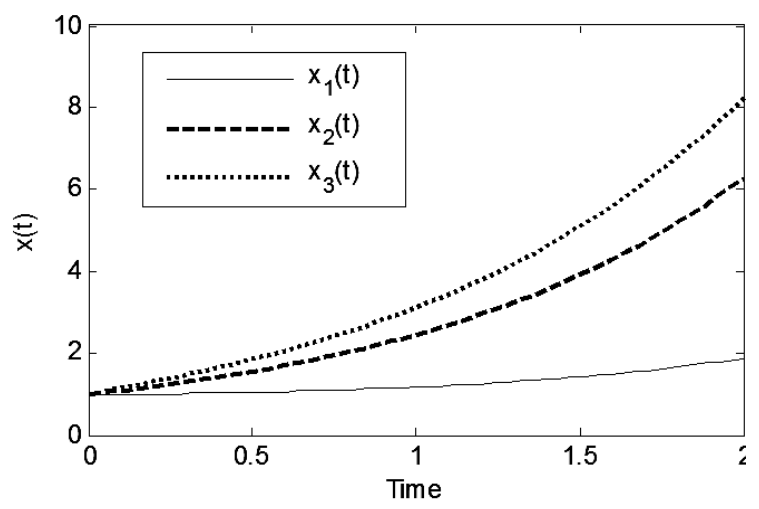

Figure 1 - The state response $\boldsymbol{x}(t)$ of the system

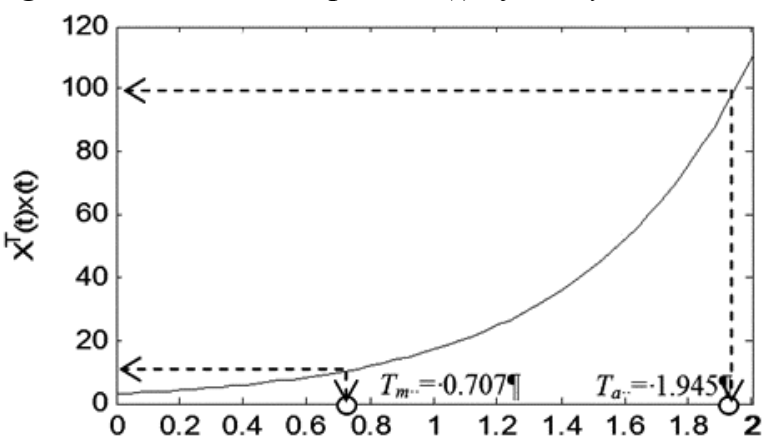

Figure 2 - The square norm of state vector

It is observed that the state variables $x_{i}(\infty) \rightarrow \infty$, $i=1,2,3$ which means that system (61) is not asymptotically stable.

From (38) and (42), one can find:

$$
Q(0)=\left(\begin{array}{ccc}
1.5279 & -1.7336 & 0.0994 \\
-1.2328 & 1.4145 & -0.2936 \\
-0.5249 & 0.8069 & 0.1575
\end{array}\right)
$$




$$
\begin{aligned}
& R=\left(\begin{array}{ccc}
-0.1721 & -0.0336 & 0.0994 \\
0.0672 & 0.4145 & 0.4064 \\
0.1751 & 1.8069 & -0.4425
\end{array}\right), \\
& \Xi=\left(\begin{array}{ccc}
-0.3442 & 0.0335 & 0.2745 \\
0.0335 & 0.8290 & 2.2133 \\
0.2745 & 2.2133 & -0.8849
\end{array}\right),
\end{aligned}
$$

Moreover, other values are calculated as follows:

$$
\begin{aligned}
& \lambda_{\max }\left\{Q(0) Q^{T}(0)\right\}=9.8109, \mu(R)=1.1789, \\
& \psi=1.1064, \lambda_{\max }\{\Xi\}=2.3578 .
\end{aligned}
$$

It is easy to show that:

$$
Q(0)>0 \text {, }
$$

as well as:

$$
Q(0,1)=e^{R \tau} Q(0)=e^{R \times 0,1} Q(0)=\left(\begin{array}{ccc}
1.5 & -1.7 & 0.1 \\
-1.3 & 1.5 & -0.3 \\
-0.7 & 1 & 0.1
\end{array}\right)>0
$$

so all conditions of Theorem 4, are satisfied.

In the sequel, the finite time stability with respect to $\left\{\alpha, \beta, T=T_{m}\right\}$, with particular choice of $\alpha=3$, for value $\beta=100$, is investigated.

It was necessary to find the maximum allowed upper bound of $T, T_{\max }=T_{\text {est }}$, for the time interval $[0, T]$ so system (61) is FTS.

Table 1 lists the comparison of $T_{\max }=T_{\text {est }}$ for specific value of the parameter $\beta=100$, using various methods presented in Theorem 1 [17], Theorem 2 [18], Theorem 3 [21], Theorem 4 [23] and Theorem 4 (this study) .

By simulating system (61), the actual values of parameter $T, T_{a}=1.945$ are estimated from the norm of state vector. The results are presented in Table 1.

Table 1. Upper bound of T, $T_{\max }=T_{\text {est }}$

\begin{tabular}{|l|l|l|}
\hline \multicolumn{2}{|c|}{$\alpha=3, \beta=100, T_{a}=1.945[s]$} & $T_{\max }=T_{\text {est }}[s]$ \\
\hline Theorem \# & Study & Result \\
\hline 1 & {$[17]$} & 0.585 \\
\hline 2 & {$[18]$} & 0.448 \\
\hline 3 & {$[21]$} & 1.225 \\
\hline 4 & $\begin{array}{l}{[23], \text { same as }[23],} \\
\text { no uncertainties }\end{array}$ & $0.707(\wp=0.2865)$ \\
\hline 4 & This study & 1.1308 \\
\hline
\end{tabular}

Furthermore, corresponding values of the parameter $\wp$ (Theorem 4, [23]) are given in Table 1.
It is calculated that Theorem 4 (this study) gives noticeably better results than all other obtained using the previous Theorems. However, unlike Theorem 3 which uses LMI, Theorem 4 [23] is based on algebraic inequalities only.

That inequality can be solved without using appropriate optimization methods.

\section{CONCLUSION}

This paper extends some of the basic results in the area of the non-Lyapunov stability to the linear continuous invariant time-delay systems.

Under certain assumptions, the new sufficient, delay-dependent criteria for the finite time stability has been presented.

The derived result is based on algebraic inequalities only, which can be solved without using appropriate optimization methods. It has been shown that, under some circumstances, the conditions derived in this study leads to significant improvement in the finite time stability analysis, particularly in comparison with results given in [23], [24]

\section{ACKNOWLEDGMENT}

This work has been supported by the Ministary of Science and Technological Department of Serbia under the Project ON 174001.

\section{REFERENCES}

[1] Dorato P, Short time stability in linear time-varying system, Proc. IRE Internat. Conv. Rec. Part 4, New York, pp. 83-87, 1961.

[2] Weiss L, Infante E. F, Finite-time stability under perturbing forces and on product spaces, IEEE Trans. Autom. Control, Vol. 12, pp. 54-59, 1967.

[3] Angelo H. D, Linear time-varying systems: analysis and synthesis, Allyn Bacon, Boston, 1970.

[4] Amato F, Ariola M, Dorato P, State feedback stabilization over a finite-time interval of linear systems subject to norm bounded parametric uncertainties, Proc. of the 36th Allerton Conference, Monticello, Sept. 23-25, 1998.

[5] Amato F, Ariola M, Dorato P, Finite-time control of linear systems subject to parametric uncertainties and disturbances, Automatica, Vol. 37, No. 9, pp. 14591463, 2001.

[6] Amato F, Ariola M, Cosentino C, Abdallah C. T, Dorato $\mathrm{P}$, Necessary and sufficient conditions for finite-time stability of linear systems, Proc. of American Control Conference, Denver, Colorado, June 2003, pp. 4452-4456, 2003. 
[7] Amato F, Ariola M, Dorato P, Finite-time stabilization via dynamic output feedback, Automatica, Vol. 42, pp. 337-342, 2006.

[8] Moulay E, Perruquetti W, Finite-time stability and stabilization of a class of continuous systems, $J$. Math. Anal. Appl., Vol. 323, pp.1430-1443, 2006.

[9] Ming Q, Shen Y, Finite-time Hळ control for linear continuous system with norm-bounded disturbance, Commun. Nonlinear Sci. Numer. Simul., Vol. 14, pp. 1043-1049, 2009.

[10]Garcia G, Tarbouriech S, Bernussou J, Finite-time stabilization of linear time-varying continuous systems, IEEE Trans. Autom. Control, Vol. 54, pp. 364 $369,2009$.

[11]Li P, Zheng Z, Global finite-time stabilization of planar nonlinear systems with disturbance, Asian $J$. Control, Vol. 14, No. 3, pp. 851-858, 2012.

[12]D. Lj. Debeljkovic, Z. Lj. Nenadic, S. A. Milinkovic, M. B. Jovanovic, On practical and finite-time stability of time-delay systems, Proc. Eur. Control Conf., Brussels, Belgium, pp. 307-311, 1997.

[13]Nenadic Z. Lj, Debeljkovic D. Lj ,Milinkovic S. A, On practical stability of time delay systems, Proc. American. Control Conference, Albuquerque, NM, USA, pp. 3235-3235, 1997.

[14]M. P. Lazarevic, D. Lj. Debeljkovic, Finite time stability analysis of linear autonomous fractional order systems with delayed state, Asian J. Control, Vol. 7, No. 4, pp. 440-447, 2005.

[15]Lazarevic M. P, Debeljkovic D. Lj, Nenadic Z. Lj. Milinkovic S. A, Finite-time stability of delayed systems, IMA J. Math. Control Inf., Vol. 17 No. 2, pp. 101-109, 1999.

[16]Debeljkovic D. Lj, Lazarevic M. P, Koruga Dj, Milinkovic S. A, Jovanovic, M. B.,Further results on the stability of linear nonautonomous systems with delayed state defined over finite time interval, Proc. Am. Control Conf., Chicago, IL, USA, pp. 1450 1451, 2000.

[17]Debeljkovic D. Lj, Buzurovic I. M, Nestorovic T, Popov D, On Finite and Practical Stability of Time
Delayed Systems: Lyapunov-Krassovski Approach: Delay Dependent Criteria, Proc. the 23rd IEEE Chinese Control and Decision Conference CCDC, Mianyang, China, March 23-25, pp.331 - 337, 2011.

[18]Debeljkovic D. Lj, Stojanovic S. B, Jovanovic A. M, Further Results on Finite Time and Practical Stability of Continuous Time Delay Systems, FME Transactions, Vol. 41, No. 3, 241 - 249, 2013.

[19]Stojanovic S. B, Debeljkovic D. Lj, Delay-dependent stability analysis for discrete-time systems with time varying state delay, Chemical Industry \& Chemical Engineering Quarterly, Vol. 17 No. 4, 497-504, 2011.

[20]Stojanovic S. B, Debeljkovic D. Lj, Dimitrijevic N, Finite-time stability of discrete-time systems with time-varying delay, Chemical Industry and Chemical Engineering, Vol 18, No 4/I, 2012.

[21]Stojanovic S. B, Debeljkovic D. Lj, Antic D. S, Finite Time Stability and Stabilization of Linear Time Delay Systems, Facta Universitatis, Series Automatic Control and Robotics, Vol.11, No.1, pp. 25 - 36, 2012.

[22]S. B. Stojanovic, D. Lj. Debeljkovic, D. S. Antic, Robust finite-time stability and stabilization of linear uncertain time-delay systems, Asian Journal of Control, Vol. 16, No. 2, pp. 1-7, 2013.

[23]Lee T. N, Diant S, Stability of time-delay systems, IEEE Transactions on Automatic Control, Vol. 26, No. 4, pp. 951-953, 1981.

[24]Debeljkovic D. Lj, Stojanovic S. B, Jovanovic A. M, Finite time stability of continuous time delay systems: A new algebraic inequalities approach, Acta Hungarica, Volume 10, Issue 7, 2013.

[25]Debeljkovic D. Lj, Buzurovic I. M, Dimitrijevic N. J, Misic M. A, Finite Time Stability of Continuous Time Delay Systems: Jensen's Inequality-based Approach, Proc. of The 9 th IEEE Conference on Industrial Electronics and Application (ICIEA 2014), June $09-$ 11, Hangzhou (China), pp. 24 - 30. ISNN 978-14799-4315-9/14/\$31.00_c 2014 IEEE 


\section{REZIME}

\section{POBOLJŠANI REZULTATI PO PITANJU STABILNOSTI SISTEMA SA KAŠNJENJEM NA KONAČNOM VREMENSKOM INTERVALU: PRILAZ SA POZICIJA JENSENOVE NEJEDNAČINE}

U ovom radu razmatra se stabilnost na konačnom vremenskom interval jedne posebne klase vremeski neprekidnih Sistema sa kašnjenjem. Iskorišćen je novi oblik agregacione funkcije, tj. kvazi-Ljapunovljev funkcional kako bi se došlo do novih dovoljnih uslova ovog koncepta stabilnosti $i$ to u formi koja uključuje i iznos čisto vremenkog kašnjenja. Predložena agregaciona funkcija ne mora da poseduje pozitivnu određenost u celom prostoru stanja, niti njen vremenski izvod duž kretanja sistema mora da bude negativno određen. Izloženi postupak, je kroz primer, upoređen sa ranijim rezultatima i pokazano je da je daleko jednostavniji sa numeričke tačke gledišta a u određenim prilikama daje $i$ manje konzervativnije rezultate od postojećih za ovu klasu razmatranih sistema.

Ključne reči: Vremenski neprekidni sistemi sa kašnjenjem, Stabilnost na konačnom vremenskom intervalu, algebarske nejednačine 